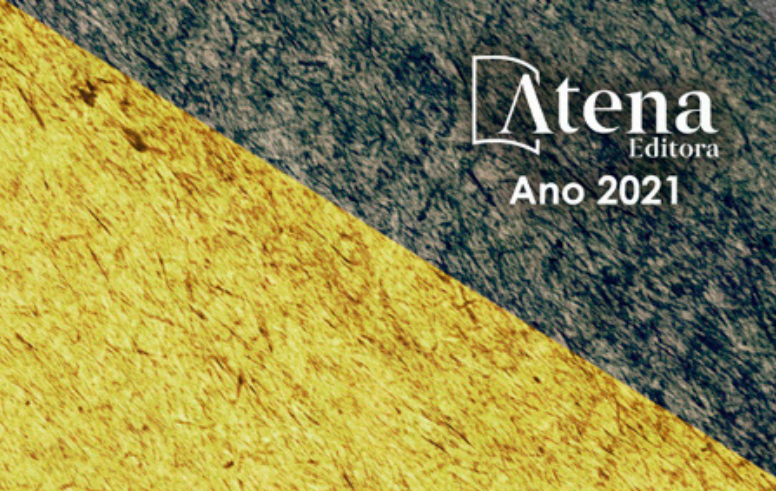

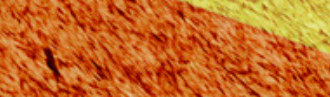

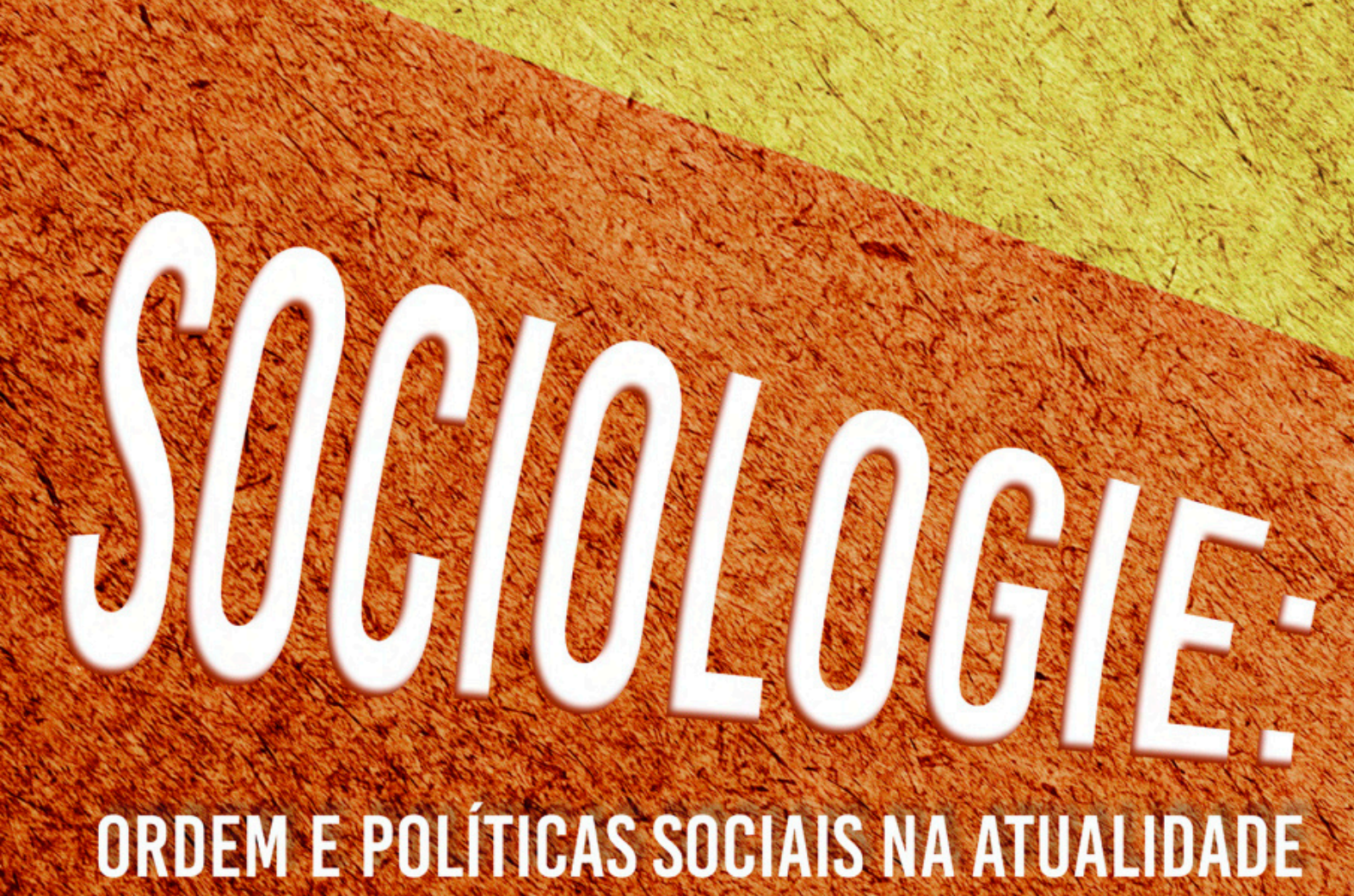

\title{
tat $x^{2}+x^{2}$ \\ MARCELO MÁXIMO PURIFICAÇÃO MARIA FILOMENA RODRIGUES TEIXEIRA SILVÂNIA MARIA ROSA (ORGANIZADORES)
}




\section{Editora chefe}

Prof $^{a}$ Dr $^{a}$ Antonella Carvalho de Oliveira

Editora executiva

Natalia Oliveira

Assistente editorial

Flávia Roberta Barão

Bibliotecária

Janaina Ramos

Projeto gráfico

Camila Alves de Cremo

Daphynny Pamplona

Gabriel Motomu Teshima

Luiza Alves Batista

Natália Sandrini de Azevedo

Imagens da capa

iStock

Edição de arte

Luiza Alves Batista
2021 by Atena Editora

Copyright (c) Atena Editora

Copyright do texto (c) 2021 Os autores

Copyright da edição (c) 2021 Atena Editora

Direitos para esta edição cedidos à Atena

Editora pelos autores.

Open access publication by Atena Editora

Todo o conteúdo deste livro está licenciado sob uma Licença de Atribuição Creative Commons. Atribuição-Não-ComercialNãoDerivativos 4.0 Internacional (CC BY-NC-ND 4.0).

O conteúdo dos artigos e seus dados em sua forma, correção e confiabilidade são de responsabilidade exclusiva dos autores, inclusive não representam necessariamente a posição oficial da Atena Editora. Permitido o download da obra e o compartilhamento desde que sejam atribuídos créditos aos autores, mas sem a possibilidade de alterá-la de nenhuma forma ou utilizá-la para fins comerciais.

Todos os manuscritos foram previamente submetidos à avaliação cega pelos pares, membros do Conselho Editorial desta Editora, tendo sido aprovados para a publicação com base em critérios de neutralidade e imparcialidade acadêmica.

A Atena Editora é comprometida em garantir a integridade editorial em todas as etapas do processo de publicação, evitando plágio, dados ou resultados fraudulentos e impedindo que interesses financeiros comprometam os padrões éticos da publicação. Situações suspeitas de má conduta científica serão investigadas sob o mais alto padrão de rigor acadêmico e ético.

\section{Conselho Editorial}

\section{Ciências Humanas e Sociais Aplicadas}

Prof. Dr. Alexandre Jose Schumacher - Instituto Federal de Educação, Ciência e Tecnologia do Paraná

Prof. Dr. Américo Junior Nunes da Silva - Universidade do Estado da Bahia

Prof $^{a}$ Dr $^{\text {a }}$ Andréa Cristina Marques de Araújo - Universidade Fernando Pessoa

Prof. Dr. Antonio Carlos Frasson - Universidade Tecnológica Federal do Paraná

Prof. Dr. Antonio Gasparetto Júnior - Instituto Federal do Sudeste de Minas Gerais

Prof. Dr. Antonio Isidro-Filho - Universidade de Brasília

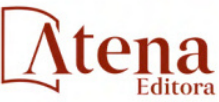


Prof. Dr. Arnaldo Oliveira Souza Júnior - Universidade Federal do Piauí

Prof. Dr. Carlos Antonio de Souza Moraes - Universidade Federal Fluminense

Prof. Dr. Crisóstomo Lima do Nascimento - Universidade Federal Fluminense

Prof $^{\mathrm{a}} \mathrm{Dr}^{\mathrm{a}}$ Cristina Gaio - Universidade de Lisboa

Prof. Dr. Daniel Richard Sant'Ana - Universidade de Brasília

Prof. Dr. Deyvison de Lima Oliveira - Universidade Federal de Rondônia

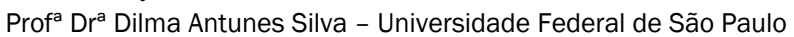

Prof. Dr. Edvaldo Antunes de Farias - Universidade Estácio de Sá

Prof. Dr. Elson Ferreira Costa - Universidade do Estado do Pará

Prof. Dr. Eloi Martins Senhora - Universidade Federal de Roraima

Prof. Dr. Gustavo Henrique Cepolini Ferreira - Universidade Estadual de Montes Claros

Prof. Dr. Humberto Costa - Universidade Federal do Paraná

Prof $^{\mathrm{a}} \mathrm{Dr}^{\mathrm{a}}$ Ivone Goulart Lopes - Istituto Internazionele delle Figlie de Maria Ausiliatrice

Prof. Dr. Jadson Correia de Oliveira - Universidade Católica do Salvador

Prof. Dr. José Luis Montesillo-Cedillo - Universidad Autónoma del Estado de México

Prof. Dr. Julio Candido de Meirelles Junior - Universidade Federal Fluminense

Prof ${ }^{a} \mathrm{Dr}^{\mathrm{a}}$ Lina Maria Gonçalves - Universidade Federal do Tocantins

Prof. Dr. Luis Ricardo Fernandes da Costa - Universidade Estadual de Montes Claros

Prof $^{a}$ Dr $^{a}$ Natiéli Piovesan - Instituto Federal do Rio Grande do Norte

Prof. Dr. Marcelo Pereira da Silva - Pontifícia Universidade Católica de Campinas

Prof $^{a}$ Dr $^{a}$ Maria Luzia da Silva Santana - Universidade Federal de Mato Grosso do Sul

Prof. Dr. Miguel Rodrigues Netto - Universidade do Estado de Mato Grosso

Prof. Dr.Pablo Ricardo de Lima Falcão - Universidade de Pernambuco

Prof $^{\mathrm{a}} \mathrm{Dr}^{\mathrm{a}}$ Paola Andressa Scortegagna - Universidade Estadual de Ponta Grossa

Prof $^{\mathrm{a}} \mathrm{Dr}^{\mathrm{a}}$ Rita de Cássia da Silva Oliveira - Universidade Estadual de Ponta Grossa

Prof. Dr. Rui Maia Diamantino - Universidade Salvador

Prof. Dr. Saulo Cerqueira de Aguiar Soares - Universidade Federal do Piauí

Prof. Dr. Urandi João Rodrigues Junior - Universidade Federal do Oeste do Pará

Prof $^{\mathrm{a}} \mathrm{Dr}^{\mathrm{a}}$ Vanessa Bordin Viera - Universidade Federal de Campina Grande

Prof $^{a}$ Dr $^{a}$ Vanessa Ribeiro Simon Cavalcanti - Universidade Católica do Salvador

Prof. Dr. William Cleber Domingues Silva - Universidade Federal Rural do Rio de Janeiro

Prof. Dr. Willian Douglas Guilherme - Universidade Federal do Tocantins 
Sociologie: ordem e políticas sociais na atualidade 2

\author{
Diagramação: Daphynny Pamplona \\ Correção: Maiara Ferreira \\ Indexação: Amanda Kelly da Costa Veiga \\ Revisão: Os autores \\ Organizadores: Marcelo Máximo Purificação \\ Maria Filomena Rodrigues Teixeira \\ Silvânia Maria Rosa
}

Dados Internacionais de Catalogação na Publicação (CIP)
S678 Sociologie: ordem e políticas sociais na atualidade 2 /
Organizadores Marcelo Máximo Purificação, Maria
Filomena Rodrigues Teixeira, Silvânia Maria Rosa. -
Ponta Grossa - PR: Atena, 2021.

Formato: PDF

Requisitos de sistema: Adobe Acrobat Reader Modo de acesso: World Wide Web

Inclui bibliografia

ISBN 978-65-5983-680-2

DOI: https://doi.org/10.22533/at.ed.802212911

1. Sociologia. I. Purificação, Marcelo Máximo

(Organizador). II. Teixeira, Maria Filomena Rodrigues

(Organizadora). III. Rosa, Silvânia Maria. IV. Título. CDD 301

Elaborado por Bibliotecária Janaina Ramos - CRB-8/9166

Atena Editora

Ponta Grossa - Paraná - Brasil Telefone: +55 (42) 3323-5493 www.atenaeditora.com.br contato@atenaeditora.com.br 


\section{POLÍTICAS DE AÇÃO AFIRMATIVA PARA A EDUCAÇÃO SUPERIOR: UM 'ESTADO DA QUESTÃO' SOBBRE A PARTICIPAÇÃO POLITIICA ESTUDANTIL}

Data de aceite: 01/11/2021

\section{Rita de Cássia Soares de Souza Bueno} Universidade Federal do Rio Grande do Sul I Faculdade de Educação I Programa de PósGraduação em Educação I Porto Alegre I RS |

Brasil

https://orcid.org/0000-0002-4254-5514

\section{Neusa Chaves Batista}

Universidade Federal do Rio Grande do Sul I Faculdade de Educação I Programa de PósGraduação em Educação I Porto Alegre I RS |

Brasil

https://orcid.org/0000-0003-4322-2829

\section{RESUMO: Esta pesquisa é de caráter bibliográfico} e procura estabelecer o 'Estado da Questão' sobre o tema das políticas de ação afirmativa para a educação superior; e da participação política de estudantes cotistas na construção das políticas afirmativas em universidades públicas. Os objetivos se prestam a delimitar e caracterizar as especificidades das produções científicas nesta área do conhecimento. As principais fontes de informação são artigos científicos, livros, teses e dissertações. O corpus de dados foi constituído por bases de dados nacionais e internacionais. Permeia nossa interpretação do objeto de estudo a perspectiva de Nancy Fraser (2010), com o enfoque priorizado nas pessoas de direito, que se justifica pelo entendimento de que estas são o centro da política e, como tal, produzem demandas e justificativas por justiça social que necessitam ser (res)significadas nas instituições deliberativas do Estado. O estudo analisa em torno de mil e quinhentas fontes de informações especializadas, constatando que nas investigações, quantitativas e/ou qualitativas, sobre política afirmativa para a Educação Superior, predominam abordagens sobre raça, racismo e relações raciais no Brasil. Os resultados obtidos apontam que há escassez da abordagem indireta e inexistência de abordagem direta sobre a temática priorizada em nosso estudo. As investigações que tratam de forma indireta da participação de estudantes cotistas no processo de construção das ações afirmativas junto às universidades indicam que, embora tais instituições apresentem progresso nas pautas de participação política, de responsabilização deliberativa e consultiva dos grupos e pessoas de direitos na produção de sentidos para as políticas públicas, ainda possuem um modelo de gestão educacional permeado pelo conservadorismo, que aflora (ainda mais) em períodos de tensão social e econômica, como na atualidade.

PALAVRAS-CHAVE: Educação Superior; Justiça Social; Política Afirmativa; Participação Estudantil.

\section{AFFIRMATIVE ACTION POLICIES FOR} HIGHER EDUCATION: A 'STATUS OF THE QUESTION' ABOUT STUDENT POLITICAL PARTICIPATION

ABSTRACT: This research is bibliographical in nature and seeks to establish the 'State of the Question' on the theme of affirmative action policies for higher education; and the political participation of quota students in the construction of affirmative policies in public universities. The 
objectives are intended to delimit and characterize the specificities of scientific production in this area of knowledge. The main sources of information are scientific articles, books, theses and dissertations. The data corpus consisted of national and international databases. The perspective of Nancy Fraser (2010) permeates our interpretation of the object of study, with a prioritized focus on people with rights, which is justified by the understanding that they are the center of politics and, as such, produce demands and justifications for social justice that need to be (re)signified in the deliberative institutions of the State. The study analyzes around fifteen hundred sources of specialized information, noting that quantitative and/or qualitative investigations on affirmative policy for Higher Education predominate approaches to race, racism and racial relations in Brazil. The results obtained show that there is a scarcity of an indirect approach and a lack of a direct approach on the theme prioritized in our study. The investigations that indirectly deal with the participation of quota students in the process of building affirmative action with universities indicate that, although such institutions show progress in the agendas of political participation, deliberative and consultative accountability of groups and people with rights in the production of meanings for public policies, they still have an educational management model permeated by conservatism, which emerges (even more) in periods of social and economic tension, such as today.

KEYWORDS: Higher Education; Social justice; Affirmative Policy; Student Participation

\section{I INTRODUÇÃO}

As políticas afirmativas constituem-se em ações públicas implantadas em países ao redor do mundo com o objetivo de garantir equidade (igualdade de oportunidades) às pessoas e a grupos sociais excluídos do acesso de bens produzidos pela humanidade. De 2001 a 2011, algumas universidades públicas brasileiras por meio dos seus conselhos universitários e com base no preceito constitucional da autonomia universitária passaram a implementar diferentes tipos de ação afirmativa. Em 2012, essa política se intensifica por meio da promulgação da Lei Federal $n^{\circ}$. 12.711 (Lei de Cotas), a qual estabelece que no mínimo $50 \%$ das vagas para todos os cursos de graduação das Instituições Federais de Educação Superior (IFES) devem ser reservadas para as/os estudantes oriundos de escolas públicas, com recortes socioeconômico e étnico-racial (BRASIL, 2012).

Nesse processo, a política afirmativa para a educação superior se tornou objeto de estudo global para muitas(os) pesquisadoras(res) a partir de diferentes abordagens, favorecendo o acúmulo de conhecimento no campo de estudo. Com esta base, nosso interesse se expressa em descrever e analisar as produções científicas sobre a temática, enfocando em investigações que abordem a participação de estudantes cotistas no processo de construção das ações afirmativas junto às universidades brasileiras.

$O$ enfoque priorizado nas pessoas de direito se justifica pelo entendimento de que estas são o centro da política e, como tal, produzem demandas e justificativas por justiça social que necessitam ser (res)significadas nas instituições deliberativas do Estado. Permeia nossa interpretação do fenômeno da política afirmativa para a educação superior 
a perspectiva de Fraser (2010), que põe em destaque três dimensões para a justiça social: socioeconômica, cultural e política. Na primeira dimensão, a demanda e luta por justiça se dá no âmbito da justa redistribuição dos recursos econômicos com vistas a transformar estruturas econômicas básicas de exploração de classe, diz respeito à classe social; na segunda dimensão, a luta se dá pelo reconhecimento de igual status a todas as pessoas e grupos em interação no espaço social, com vistas a uma mudança cultural ou simbólica e diz respeito às identidades culturais; a terceira dimensão oferece o palco, a esfera pública, sobre o qual as lutas por redistribuição e reconhecimento se materializam por meio da disputa pela participação das pessoas de direitos na produção de sentidos para as políticas públicas.

Metodologicamente, realizamos uma pesquisa bibliográfica do tipo "Estado da Questão" (Therrien \& Therrien, 2004), com o objetivo de mapear, delimitar e caracterizar as especificidades da temática investigada, bem como procedemos à identificação, definição e análise das categorias centrais das abordagens teórico-metodológicas utilizadas pelas(os) pesquisadoras(res). O recorte de área ficou restrito às ciências humanas. Não houve recorte temporal, já que foram incluídas no estudo as produções acadêmicas que: a) antecedam a implementação da primeira ação afirmativa em universidades públicas brasileiras (até 2001); b) sucedam a implementação da primeira ação afirmativa em universidades públicas brasileiras (2002-2012); c) sucedam a aprovação da Lei Federal de Cotas de 2012 (20132019).

Este esquema, na coleta de dados, teve como objetivo obter um panorama que abrangesse todos os ciclos da política educacional em estudo. As principais fontes de informação foram: artigos científicos, livros, teses e dissertações. O corpus de dados foi constituído por bases de dados nacionais e internacionais. O estudo analisa em torno de mil e quinhentas fontes de informações especializadas, constatando que nas investigações, quantitativas e/ou qualitativas, sobre política afirmativa para a Educação Superior, predominam abordagens sobre raça, racismo e relações raciais no Brasil.

Ademais, os resultados obtidos apontam que há escassez da abordagem indireta e inexistência de abordagem direta sobre a temática priorizada em nosso estudo. As investigações que tratam de forma indireta da participação de estudantes cotistas no processo de construção das ações afirmativas junto às universidades indicam que, embora tais instituições apresentem progresso nas pautas de participação política, de responsabilização deliberativa e consultiva dos grupos e pessoas de direitos na produção de sentidos para as políticas públicas, ainda possuem um modelo de gestão educacional permeado pelo conservadorismo, que aflora (ainda mais) em períodos de tensão social e econômica, como na atualidade. 


\section{I PRODUÇÕES CIENTÍFICAS SOBRE POLÍTICAS DE AÇÃO AFIRMATIVA PARA A EDUCAÇÃO SUPERIOR E A PARTICIPAÇÃO POLÍTICA ESTUDANTIL}

A presente análise converge para um panorama quantitativo e qualitativo a partir da sistematização das informações encontradas nas consultas ao tema geral das políticas de ação afirmativa para a educação superior, ao específico da participação política de estudantes cotistas na construção das políticas afirmativas em universidades públicas e às suas respectivas abordagens em 3(três) fontes de informações especializadas e em 6(seis) bases de dados, nacionais e internacionais.

\begin{tabular}{|l|c|c|}
\hline \multicolumn{2}{|c|}{$\begin{array}{c}\text { Fontes de Informações } \\
\text { Especializadas }\end{array}$} & \multicolumn{2}{c|}{ Bases de Dados } \\
\cline { 2 - 3 } & Nacional & Internacional \\
\hline 1) Artigos & Periódico SciELO & Periódico Scopus \\
\hline 2) Livros & Periódico CAPES & Biblioteca WorldCat \\
\hline 3) Teses e Dissertações & Catálogo CAPES & Catálogo OATD \\
\hline
\end{tabular}

Quadro 1 - Fontes de informações e as bases de dados

Fonte: Elaborado pelas autoras a partir da pesquisa autoral de caráter bibliográfico.

As escolhas e as construções de pesquisa não esgotam as produções de conhecimento sobre as temáticas em questão. Entretanto, podem se aproximar do número de produções existente nas bases de dados e nos sites consultados. A partir dos recursos de refinamento disponíveis nas plataformas, utilizamos os seguistes critérios de busca:

\begin{tabular}{|l|l|}
\hline Língua/ldioma & Todos \\
\hline Ano de Publicação & Todos \\
\hline Área de Conhecimento & Ciências Humanas \\
\hline Termos de Busca & $\begin{array}{l}\text { ("ação afirmativa" OR "ações afirmativas" OR cota OR cotas) AND } \\
\text { (universidade OR universidades OR "educação superior" OR } \\
\text { "ensino superior") }\end{array}$ \\
\cline { 2 - 2 } & $\begin{array}{l}\text { ("affirmative action" OR quotas) AND (university OR "higher } \\
\text { education") }\end{array}$ \\
\hline
\end{tabular}

Quadro 2 - Critérios de busca avançada

Fonte: Elaborado pelas autoras a partir da pesquisa autoral de caráter bibliográfico.

Após o levantamento e armazenamento, fizemos a leitura de todos os títulos e resumos das fontes, buscando identificar quais tratavam do tema geral sob alguma forma de análise. De posse dessa informação, organizamos um panorama das quantificações por ciclos da política e principais abordagens. No total, foram localizadas 1.488 (mil quatrocentas e oitenta e oito) fontes. Entretanto, foram incluídas no estudo 959 (novecentas e cinquenta e nove), 
sendo 209 (duzentos e nove) artigos, 168 (cento e sessenta e oito) livros e 582 (quinhentas e oitenta e duas) teses e dissertações. Distribuídas em cada ciclo da política pública de ação afirmativa em universidades públicas brasileiras, conforme porcentagens no gráfico abaixo:

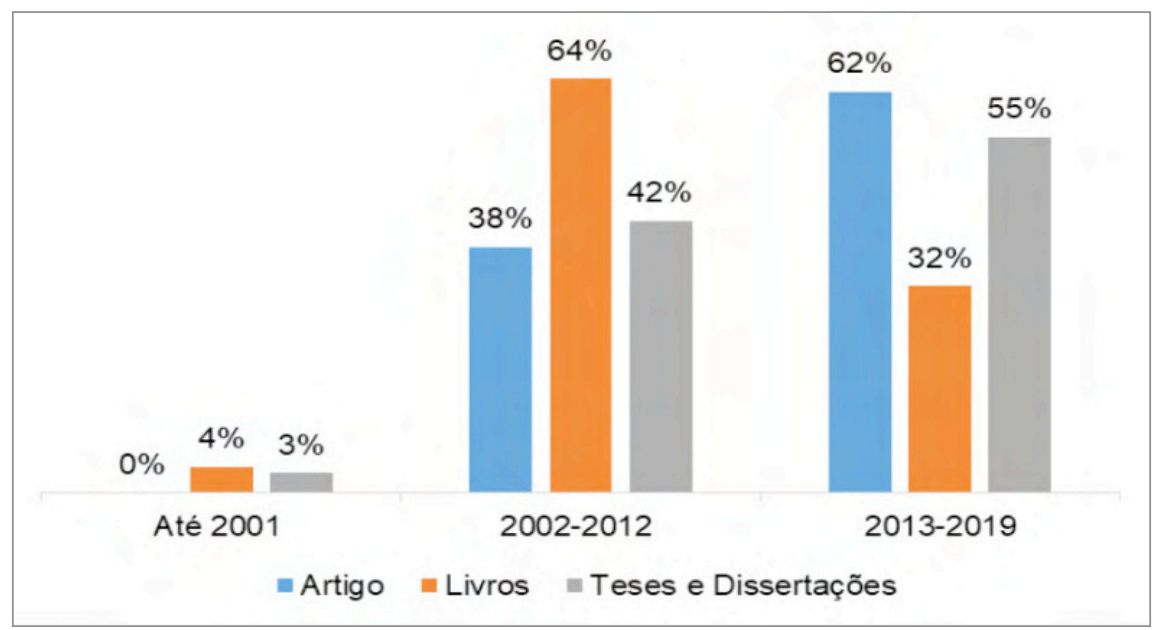

Gráfico 1 - Porcentagens de produções científicas em cada ciclo da política afirmativa em universidades

Fonte: Elaborado pelas autoras a partir da pesquisa autoral de caráter bibliográfico.

Dentre essas produções sobre o tema geral, verificamos quais estavam relacionadas diretamente com a temática específica ou quais apresentavam alguma intersecção, procedendo a leitura na íntegra. A partir das leituras, sistematizamos as informações sobre o título, autor(es), ano de publicação, tipo de produção, campo do conhecimento, objetivos, objeto de estudo, enfoque metodológico e principais resultados. Quando necessário, adaptamos as variáveis a cada uma das fontes. Por fim, ensaiamos uma análise qualitativa das produções encontradas.

\subsection{ARTIGOS NAS COLEÇÕES DE PERIÓdICOS DA SCIELOE SCOPUS}

$\mathrm{Na} S \operatorname{SiELO}{ }^{1}$ e na Scopus ${ }^{2}$ identificamos 230(duzentos e trinta) artigos acadêmicos e procedemos à leitura dos títulos e resumos. 


\begin{tabular}{|c|c|l|}
\hline Base (Artigos) & $\begin{array}{c}\text { Registros } \\
\text { Recuperados }\end{array}$ & \multicolumn{1}{|c|}{ Endereço eletrônico e data de acesso } \\
\hline $\begin{array}{c}\text { SciELO } \\
\text { (Nacional) }\end{array}$ & $\begin{array}{c}141 \\
(2002 \text { a } 2019)\end{array}$ & $\begin{array}{l}\text { <Disponivel em: http://wnww.scielo.br/?Ing=pt. Acesso } \\
\text { em: 12/07/2019> }\end{array}$ \\
\hline $\begin{array}{c}\text { Scopus } \\
\text { (Internacional) }\end{array}$ & $\begin{array}{c}89 \\
(2000 \text { a 2019) }\end{array}$ & $\begin{array}{l}\text { <Disponivel em: } \\
\text { https://www.elsevier.com/pt-br/solutions/scopus. } \\
\text { Acesso em: } 12 / 07 / 2019>\end{array}$ \\
\hline
\end{tabular}

Tabela 1 - Registros de artigos identificados

Fonte: Elaborado pelas autoras a partir da pesquisa autoral de caráter bibliográfico.

A partir da leitura dos títulos e resumos excluímos 21(vinte e um) artigos, pois não tratavam do tema geral. Incluímos no estudo 209(duzentos e nove), cujas informações apontam para uma predominância de abordagem da temática 'ação afirmativa racial' (38\%) e 'ação afirmativa racial e social' (19\%) na educação superior. Os enfoques são nas relações raciais, raça e racismo no Brasil; e suas intersecções com as ações afirmativas em universidades e/ou nos cursos de graduação.

Dos 209 (duzentos e nove) artigos que tratavam sobre as 'políticas de ação afirmativa para a educação superior', apenas 04(quatro) possuíam alguma intersecção com o tema específico da 'participação política estudantil', os quais selecionamos para ensaiar algumas análises, conforme segue:

\begin{tabular}{|c|c|c|c|c|c|}
\hline Título do Artigo & $\begin{array}{l}\text { Autora(as) do } \\
\text { Texto }\end{array}$ & $\begin{array}{c}\text { Ano de } \\
\text { Publicação }\end{array}$ & $\begin{array}{l}\text { Revista } \\
\text { que } \\
\text { Publicou }\end{array}$ & Área & $\begin{array}{c}\text { Qualis } \\
\text { (Consulta: } \\
\text { 06/10/2019) }\end{array}$ \\
\hline $\begin{array}{l}\text { Democratização, } \\
\text { justiça social e } \\
\text { igualdade na } \\
\text { avaliação de uma } \\
\text { politica afirmativa: } \\
\text { com a palavra, os } \\
\text { estudantes. }\end{array}$ & $\begin{array}{l}\text { - Andreliza } \\
\text { Cristina de } \\
\text { Souza; } \\
\text { - Mary Ângela } \\
\text { Teixeira } \\
\text { Brandalise. }\end{array}$ & 2015 & $\begin{array}{l}\text { Ensaio: } \\
\text { Avaliação e } \\
\text { Políticas } \\
\text { Públicas } \\
\text { em } \\
\text { Educação }\end{array}$ & Educação & A1 \\
\hline $\begin{array}{l}\text { Relações raciais, } \\
\text { cultura acadêmica e } \\
\text { tensionamentos } \\
\text { após ações } \\
\text { afirmativas }\end{array}$ & $\begin{array}{l}\text { - Joana Célia dos } \\
\text { Passos. }\end{array}$ & 2015 & $\begin{array}{l}\text { Educação } \\
\text { em Revista }\end{array}$ & Educação & $\mathrm{A} 1$ \\
\hline $\begin{array}{l}\text { Cidadania, } \\
\text { reconhecimento e } \\
\text { ação afirmativa no } \\
\text { ensino superior }\end{array}$ & $\begin{array}{l}\text { - Ângela } \\
\text { Rodolpho Paiva. }\end{array}$ & 2015 & $\begin{array}{l}\text { Civitas - } \\
\text { Revista de } \\
\text { Ciências } \\
\text { Sociais }\end{array}$ & $\begin{array}{l}\text { Ciências } \\
\text { Sociais }\end{array}$ & B2 \\
\hline $\begin{array}{l}\text { Políticas públicas de } \\
\text { ações afirmativas } \\
\text { para a Educação } \\
\text { Superior: o Conselho } \\
\text { Universitário como } \\
\text { arena de disputas }\end{array}$ & $\begin{array}{l}\text { - Neusa Chaves } \\
\text { Batista. }\end{array}$ & 2015 & $\begin{array}{l}\text { Ensaio: } \\
\text { Avaliação e } \\
\text { Políticas } \\
\text { Públicas } \\
\text { em } \\
\text { Educacão }\end{array}$ & Educação & $\mathrm{A} 1$ \\
\hline
\end{tabular}

Quadro 3 - Informações básicas sobre os artigos em periódicos

Fonte: Elaborado pelas autoras a partir da pesquisa autoral de caráter bibliográfico. 
Todos os artigos são de divulgação de pesquisas e apresentam revisões de literatura e reflexões teóricas sobre a democratização e as ações afirmativas na Educação Superior; bem como, reflexões teórico-empíricas sobre justiça social, cidadania e reconhecimento para estudantes cotistas em universidades públicas brasileiras. Após a leitura na íntegra, foi possível sistematizar os objetivos, objeto de estudo, enfoque metodológico, fontes e principais resultados, conforme o quadro abaixo:

\begin{tabular}{|c|c|c|c|c|}
\hline & $\begin{array}{c}\text { Souza \& } \\
\text { Brandalise } \\
(2015)\end{array}$ & $\begin{array}{l}\text { Passos } \\
\text { (2015) }\end{array}$ & $\begin{array}{l}\text { Paiva } \\
\text { (2015) }\end{array}$ & $\begin{array}{l}\text { Batista } \\
(2015)\end{array}$ \\
\hline Objetivos & $\begin{array}{l}\text { - Desvelar se a } \\
\text { politica de cotas } \\
\text { de uma } \\
\text { instituição de } \\
\text { Ensino Superior } \\
\text { paranaense, na } \\
\text { percepção dos } \\
\text { estudantes que } \\
\text { a ela recorreram } \\
\text { para ingresso } \\
\text { nos cursos de } \\
\text { graduação, } \\
\text { favorece ou } \\
\text { possibilita a } \\
\text { democratização } \\
\text { do acesso a a } \\
\text { promoção da } \\
\text { igualdade e da } \\
\text { justiça social (p. } \\
\text { 181). }\end{array}$ & $\begin{array}{l}\text { - Analisar a } \\
\text { cultura } \\
\text { acadêmico- } \\
\text { curricular e } \\
\text { suas } \\
\text { configurações } \\
\text { derivadas da } \\
\text { presença de } \\
\text { estudantes } \\
\text { negros/negras } \\
\text { cotistas no } \\
\text { cotidiano da } \\
\text { Universidade } \\
\text { Federal de } \\
\text { Santa } \\
\text { Catarina. }\end{array}$ & $\begin{array}{l}\text { - Discutir a fruição } \\
\text { de direitos } \\
\text { humanos para a } \\
\text { construção da } \\
\text { cidadania no } \\
\text { Brasil; } \\
\text { - Destacar fatores } \\
\text { determinantes } \\
\text { para a } \\
\text { organização } \\
\text { social de } \\
\text { movimentos } \\
\text { sociais negros; } \\
\text { - Tecer } \\
\text { contextualização } \\
\text { e conceituação } \\
\text { dos direitos e } \\
\text { demandas por } \\
\text { reconhecimento. }\end{array}$ & $\begin{array}{l}\text { - Analisar os } \\
\text { principais } \\
\text { impasses, } \\
\text { conflitos e } \\
\text { contradições da } \\
\text { politica de ações } \\
\text { afirmativas da } \\
\text { UFRGS, na } \\
1.151^{a} \text { sessão do } \\
\text { Conselho } \\
\text { Universitário } \\
\text { realizada em } \\
2012, \text { que tinha } \\
\text { como objetivo } \\
\text { avaliar os } \\
\text { primeiros cinco } \\
\text { anos da } \\
\text { implantação da } \\
\text { politica. }\end{array}$ \\
\hline $\begin{array}{l}\text { Objeto de } \\
\text { Estudo }\end{array}$ & $\begin{array}{l}\text { - Política de } \\
\text { 'acesso' por } \\
\text { ação afirmativa, } \\
\text { cotas sociais. }\end{array}$ & $\begin{array}{l}\text { - Acesso e } \\
\text { permanência } \\
\text { material e } \\
\text { simbólica dos } \\
\text { cotistas étnico- } \\
\text { raciais. }\end{array}$ & $\begin{array}{l}\text { - Ação do } \\
\text { movimento negro } \\
\text { e a controvérsia } \\
\text { das 'cotas } \\
\text { raciais'. }\end{array}$ & $\begin{array}{l}\text { - Embates e } \\
\text { disputas } \\
\text { estabelecidos } \\
\text { pelos atores } \\
\text { politicos, em } \\
\text { especial o } \\
\text { impasse que se } \\
\text { estabelece entre } \\
\text { os segmentos } \\
\text { docente e } \\
\text { discente, no que } \\
\text { se refere ao } \\
\text { parecer da } \\
\text { Comissão } \\
\text { Especial de } \\
\text { avaliação das } \\
\text { ações afirmativas. }\end{array}$ \\
\hline $\begin{array}{l}\text { Enfoque } \\
\text { Metodológico }\end{array}$ & Qualitativo & Qualitativo & Qualitativo & Qualitativo \\
\hline Fontes & $\begin{array}{l}\text { Questionário e } \\
\text { entrevista com } \\
\text { estudantes. }\end{array}$ & $\begin{array}{l}\text { - Documentos } \\
\text { normativos; } \\
\text { - Projetos } \\
\text { Político } \\
\text { Pedagógicos } \\
\text { (PPP); } \\
\text { - Questionário } \\
\text { com } \\
\text { professores e } \\
\text { coordenadores } \\
\text { de curso; } \\
\text { - Depoimento } \\
\text { de estudantes } \\
\text { negras. }\end{array}$ & $\begin{array}{l}\text { - Editais de } \\
\text { processo seletivo } \\
\text { para ingresso em } \\
\text { universidades; } \\
\text { - Formulário com } \\
\text { estudantes; } \\
\text { - Entrevista com } \\
\text { gestores. }\end{array}$ & $\begin{array}{l}\text { - Documentos: } \\
\text { atas, pareceres, } \\
\text { pedidos de vistas, } \\
\text { e outros } \\
\text { documentos } \\
\text { produzidos } \\
\text { no/pelo CONSUN/ } \\
\text { UFRGS. }\end{array}$ \\
\hline
\end{tabular}

Quadro 4 - Abordagens de pesquisas em artigos de periódicos

Fonte: Elaborado pelas autoras a partir da pesquisa autoral de caráter bibliográfico.

Em relação à metodologia, observamos a utilização de estudos exclusivamente com abordagem qualitativa. Nas fontes para coleta de dados detalhadas no quadro acima, percebemos em comum que três artigos (Souza \& Brandalise, 2015; Passos, 2015; Paiva, 2015) aplicaram questionários, entrevistas e/ou formulários tendo como foco os/as 
estudantes cotistas. Para além, dois dos textos (Passos, 2015; Paiva, 2015) valeram-se da análise de documentos institucionais e entrevista com professores ou gestores. Enquanto, (Batista, 2015) utiliza os documentos: atas, pareceres e pedidos de vistas produzidos na/para a 1.151\%/2012 sessão do Conselho Universitário/UFRGS.

No artigo de Souza \& Brandalise (2015) há uma apresentação inicial de conceitos sobre políticas públicas, políticas sociais, política afirmativa e política de cotas; oferecendo discussões teóricas e empíricas sobre a democratização, justiça social e igualdade. As conceptualizações propostas apresentam-se mais como uma revisão de literatura dos conceitos tradicionais de justiça social, especialmente do ponto de vista da juridicidade, ou seja, por meio de considerações sobre justiça formal e justiça substancial.

A pesquisa de Passos (2015) traz contextualizações, panoramas, reflexões teóricas e empíricas significativas sobre o tema das 'cotas raciais', apontando para outras possibilidades de investigação sobre o tema. Coloca que os desafios institucionais a serem enfrentados no âmbito da autonomia universitária seriam a construção de soluções a partir das demandadas de movimentos sociais, da comunidade acadêmica e, sobretudo, dos estudantes cotistas. Pois, alargariam o espectro democrático das universidades públicas, eixo basilar de sua missão ante a sociedade brasileira.

Nos estudos apresentados por Paiva (2015) encontra-se um panorama contextual e conceitual sobre cidadania, esfera pública, direitos, reconhecimento, ação coletiva e identidade no Brasil e suas possibilidades de relações com a política afirmativa em universidades. A autora ressalta que tal política representa uma ação efetiva na busca parcial de reparação do déficit de oferta da educação superior para a promoção de uma cidadania democrática.

O estudo de Batista (2015) diz que na construção de futuras pesquisas seria importante a proposição de análises dos instrumentos legítimos de expressão e de participação no quinhão da autoridade institucional. Visto que, as universidades organizam-se a partir de hierarquias cujos resultados, quase sempre, resultam em desigualdade na representação dos segmentos e nos atos decisórios. No resultado de sua pesquisa empírica, constata que as proposições dos segmentos discentes foram sendo derrotadas, em sua grande maioria, até que prevalecesse a vontade oficial do que é institucional. Nesse caso, costumam prevalecer os discursos considerados legítimos do ponto de vista institucionalizado - o discurso dos docentes.

\subsection{LIVROS NAS BASES DE DADOS DA CAPES E WORLDCAT}

$\mathrm{Na}$ base de dados da CAPES $^{3}$ e da WorldCat ${ }^{4}$ identificamos 353 trezentos e cinquenta e três) livros e procedemos à leitura, analisando os títulos, e quando disponíveis, suas sinopses e sumários.

3 Catálogo da Coordenação de Aperfeiçoamento de Pessoal de Nível Superior (CAPES)

4 O WorldCat é uma rede mundial de bibliotecas 


\begin{tabular}{|c|c|l|}
\hline $\begin{array}{c}\text { Base } \\
\text { (Livros) }\end{array}$ & $\begin{array}{c}\text { Registros } \\
\text { Recuperados }\end{array}$ & \multicolumn{1}{|c|}{ Endereço eletrônico e data de acesso } \\
\hline CAPES & $\begin{array}{c}93 \\
(1996 \text { a } 2019)\end{array}$ & $\begin{array}{l}\text { <Disponivel em: http://www.periodicos.capes.gov.br/. } \\
\text { Acesso em: 08/08/2019> }\end{array}$ \\
\hline WorldCat & $\begin{array}{c}260 \\
(1993 \text { a 2019) }\end{array}$ & $\begin{array}{l}\text { <Disponivel em: } \text { https://www. worldcat.orgl. Acesso } \\
\text { em: 08/08/2019> }\end{array}$ \\
\hline
\end{tabular}

Tabela 2 - Registros de livros identificados

Fonte: Elaborado pelas autoras a partir da pesquisa autoral de caráter bibliográfico.

Após as leituras, excluímos do estudo 185(cento e oitenta e cinco) livros por serem duplicatas ou não tratarem do tema geral. Incluímos 168(cento e sessenta e oito) livros, nos quais encontramos uma predominância geral de abordagens sobre 'ação afirmativa racial' (58\%) e 'ação afirmativa racial e social' (17\%) em universidade. Especialmente, tratando das relações raciais, raça e racismo no Brasil; e suas intersecções com as ações afirmativas em universidades e/ou nos cursos de graduação.

Dos livros que abordavam o tema geral, apenas 01 (um) possuía alguma intersecção com o tema específico, o qual selecionamos para um ensaio analítico. O livro compõe a base de dados da CAPES e se intitula 'Observatório da vida estudantil: primeiros estudos'. Está disponível na íntegra, como e-book, também, na base da SciELO.

\begin{tabular}{|l|l|c|c|c|}
\hline \multicolumn{1}{|c|}{ Título do Livro } & Autora & $\begin{array}{c}\text { Ano de } \\
\text { Publicação }\end{array}$ & Editora & Área \\
\hline $\begin{array}{l}\text { Observatório da } \\
\text { vida estudantil: } \\
\text { primeiros estudos }\end{array}$ & $\begin{array}{l}\text { Sônia Maria Rocha } \\
\text { Sampaio (UFBA) }\end{array}$ & 2011 & EDUFBA & $\begin{array}{c}\text { Psicologia } \\
\text { da } \\
\text { Educação }\end{array}$ \\
\hline
\end{tabular}

Quadro 5 - Informações sobre o livro

Fonte: Elaborado pelas autoras a partir da pesquisa autoral de caráter bibliográfico.

Em sua sinopse informa que:

A obra contempla os objetivos, metodologia de trabalho e perspectivas atuais do 'Observatório da Vida Estudantil', que atua em duas Instituições Federais de Ensino Superior da Bahia - a UFBA e a UFRB. A obra, formada por 12 artigos, trata de temas como o novo universitário que vem se inserindo na UFBA, o aluno de origem popular e a opinião dos estudantes com relação ao Bacharelado Institucional. A relação da juventude com a política, a maternidade durante o período universitário, e a questão da evasão na educação superior são alguns dos assuntos também abordados (SAMPAIO, 2011).

Ao percorrer o sumário do livro encontramos apenas 1(um) artigo que possuía intersecção com o tema específico, e após a leitura na íntegra, construímos o quadro abaixo que sistematiza os objetivos, objeto de estudo, enfoque metodológico, fontes e principais 
TÍTULO DO ARTIGO

MAIA, Allan Jeffrey Vidal, et al. Juventude e política: observando a UFBA. In: SAMPAIO, Sônia Maria Rocha, org. Observatório da vida estudantil: primeiros estudos [online]. Salvador: EDUFBA, 2011, pp. 169-186.

\begin{tabular}{|c|c|}
\hline Objetivos & $\begin{array}{l}\text { - Buscar um conhecimento preliminar sobre as relações entre juventude e política na } \\
\text { UFBA (p.173). }\end{array}$ \\
\hline $\begin{array}{l}\text { Objeto de } \\
\text { Estudo }\end{array}$ & $\begin{array}{l}\text { - Participação política estudantil: significados, experiências de militâncias em } \\
\text { grupos/coletivos específicos e atuação pessoal. }\end{array}$ \\
\hline $\begin{array}{c}\text { Enfoque } \\
\text { Metodológico }\end{array}$ & $\begin{array}{l}\text { Qualitativo } \\
\text { (Pesquisa Participativa) }\end{array}$ \\
\hline Fontes & $\begin{array}{l}\text { - Diário de Campo; } \\
\text { - Entrevista semiestruturada com estudantes. }\end{array}$ \\
\hline Resultados & $\begin{array}{l}\text { - O ambiente universitário não é o único responsável pelo desencadeamento da } \\
\text { participação política dos estudantes [...] a sensibilização é feita, por diferentes } \\
\text { agentes que vão da vida familiar, passando pelo grupo de iguais e pela mídia (p. } \\
183 \text { e 184). } \\
\text { - A vinculação a movimentos políticos e sociais interfere nos itinerários de vida e na } \\
\text { constituição da subjetividade dos estudantes entrevistados, que se veem } \\
\text { existencialmente vinculados aos movimentos que integram (p. 184). } \\
\text { - A política tem efeito de vincular os sujeitos às questões do seu mundo, do seu } \\
\text { país, da sua comunidade proximal, apresentando caminhos e possibilidades de } \\
\text { ação coletiva que podem fazer enorme diferença na formação de uma pessoa, } \\
\text { sobretudo, jovens universitários, ávidos em encontrar, em meio a dilemas } \\
\text { identitários características dessa idade da vida (p.184). } \\
\text { - Os estudantes sentem: "desvalorização, pela instituição universitária, das práticas } \\
\text { políticas, de qualquer coloração ou formato, não havendo integração entre as } \\
\text { instâncias administrativas e os diferentes movimentos" [...] "preconizam outras } \\
\text { práticas institucionais, que legitimem melhor suas atividades, superando o clima de } \\
\text { confronto que, eventualmente, torna críticas essas relações" (p.184). } \\
\text { - A universidade concede espaço para articulação independente de diferentes } \\
\text { grupos. Há uma infraestrutura mínima, constituídas pelos espaços legitimados para } \\
\text { os Diretórios ou Centros Acadêmicos (DA ou CA) e Diretório Central dos Estudantes } \\
\text { (DCE), cujo funcionamento é garantido administrativamente (p. 185). } \\
\text { - Os estudantes não restringem sua movimentação política aos muros da } \\
\text { universidade, participando de ações coletivas, locais e nacionais, que reforçam seus } \\
\text { movimentos específicos, tornando-se fontes de mais aprendizagens do ponto de } \\
\text { vista de sua formação política (p. 185). } \\
\text { - O espaços políticos instituídos no meio universitário acabam se tornando portas de } \\
\text { entrada para os movimentos sociais tomarem contato com o mundo, por vezes difícil } \\
\text { de penetrar, que é a universidade (p.185). } \\
\text { - Na UFBA, diferentes segmentos da juventude continuam ativos politicamente e } \\
\text { buscam formas inovadoras de atuação (p.185). }\end{array}$ \\
\hline
\end{tabular}

Quadro 6 - Abordagem de pesquisa no artigo do livro

Fonte: Elaborado pelas autoras a partir da pesquisa autoral de caráter bibliográfico.

O artigo acima é derivado do trabalho de pesquisa e intervenção desenvolvido por 6(seis) estudantes do curso de psicologia da UFBA, nas disciplinas Psicologia Escolar I e II, sob orientação da Profa. Dra. Sônia Maria Rocha Sampaio, no ano de 2008. As/Os estudantes pesquisadoras/es MAIA et al (2011) abrem a discussão sobre a 'participação política da juventude' interrogando-se sobre o seu incremento ou declínio, nas três ou quatro 
últimas décadas, ressaltando que estudiosos do tema se dividem entre a emergência de um apolitismo juvenil ou o surgimento de nova formas de engajamento político.

Comentam que os jovens entre 15 e 25 anos são $20 \%$ da população e se encontram a margem dos processos decisórios em relação as Políticas Públicas elaboradas pelo governo brasileiro, apontando para a necessidade de ocupação desses espaços de representatividade. Ainda, afirmam que os/as jovens estão participando em grupos/coletivos de diferentes correntes políticas e ideológicas, que pleiteiam espaços de participação e que articulam ações de tipo afirmativo, tanto em caráter local quanto global. Sendo que, os múltiplos pertencimentos permitem a permeabilidade desses jovens a outros movimentos políticos, de caráter afirmativo ou de discriminação positiva (MAIA et al, 2011).

Como uma das principais colaborações e possíveis direcionamentos de futuras pesquisas, destacam que nas universidades coexistem espaços institucionalizados que permitem a participação política, funcionando como territórios legitimados de representatividades, mais voltados para as políticas estudantis e/ou educacionais, tais como: Diretórios ou Centros Acadêmicos (DA ou CA) e o Diretório Central dos Estudantes (DCE). Para além desses movimentos, trazem a possibilidade de encontrar acadêmicos vinculados a outros grupos, como por exemplo: partidos políticos; e grupos nucleados a partir de temas referente à diversidade/identidade (racial, étnica, de gênero e etc.). Em seus estudos optaram por apresentar relatos de entrevistas com representantes estudantis dos DCE, CA, DA, Movimento de Luta Antimanicomial, Movimento do Passe Livre e Movimento LGBT (MAIA et al, 2011).

\subsection{TESES E DISSERTAÇÕES NOS CATÁLOGOS DA CAPES E OATD}

$\mathrm{Na}$ base de dados da CAPES e da OATD $^{6}$ identificamos 905 (novecentos e cinco) registros de teses e dissertações acadêmicas e procedemos à leitura dos títulos e resumos, buscando identificar quais tratavam sobre tema geral e o específico.

\begin{tabular}{|c|c|c|c|l|}
\hline Base & $\begin{array}{c}\text { Registros } \\
\text { Recuperados }\end{array}$ & Teses & Dissertações & \multicolumn{1}{c|}{$\begin{array}{c}\text { Endereço eletrônico e data de } \\
\text { acesso }\end{array}$} \\
\hline CAPES & $\begin{array}{c}548 \\
(2001 \text { a } 2019)\end{array}$ & 142 & 406 & $\begin{array}{l}\text { <Disponível em: } \\
\frac{\text { https://catalogodeteses.capes.gov. }}{\text { br/catalogo-teses/\#!! } . ~ A c e s s o ~ e m: ~} \\
11 / 07 / 2019>\end{array}$ \\
\hline OATD & $\begin{array}{c}357 \\
(1979 \text { a 2019) }\end{array}$ & 104 & 253 & $\begin{array}{l}\text { <Disponível em: https://oatd.org/. } \\
\text { Acesso em: } 12 / 07 / 2019>\end{array}$ \\
\hline
\end{tabular}

Tabela 3 - Registros de teses e dissertações identificados

Fonte: Elaborado pelas autoras a partir da pesquisa autoral de caráter bibliográfico.

Após as leituras, excluímos 320(trezentos e vinte) produções, por não abordarem o

5 Catálogo da Coordenação de Aperfeiçoamento de Pessoal de Nível Superior (CAPES)

6 Open Access Theses and Dissertations (OATD) 
tema geral da pesquisa. Incluímos no estudo 582(quinhentos e oitenta) teses e dissertações. Na OATD encontramos predominância de abordagens sobre 'Ação Afirmativa no Brasil' e 'Ação Afirmativa nos EUA'; e na CAPES sobre 'Ação Afirmativa Racial' e 'Ação Afirmativa Racial e Social', que priorizam (74\%) o tema das relações raciais, raça e racismo nos respectivos países; e suas intersecções com as ações afirmativas em universidades e/ou nos cursos de graduação.

Das teses e dissertações que abordavam o tema geral das políticas de ação afirmativa na educação superior, apenas 02 (duas) possuíam alguma intersecção com o tema específico, as quais selecionamos para análises mais aprofundadas. Essas produções acadêmicas correspondem a 01 (uma) tese disponível na base de dados da CAPES e 01(uma) dissertação disponível em ambas, CAPES e OATD:

\begin{tabular}{|l|l|l|}
\hline Título & $\begin{array}{l}\text { Possibilidades e Oportunidades de } \\
\text { Atuação Política: estudo sobre a } \\
\text { formação do Grupo de Trabalho de } \\
\text { Ações Afirmativas no processo de } \\
\text { reivindicação por cotas na UFRGS }\end{array}$ & $\begin{array}{l}\text { Juventude, política e educação: a } \\
\text { emergência do estudante precarizado } \\
\text { no contexto da reforma do ensino } \\
\text { superior, sua inserção no movimento } \\
\text { estudantil e os conflitos no campo } \\
\text { político universitário }\end{array}$ \\
\hline Autor & Felipe Prolo & Fabiano Pereira Silva \\
\hline Orientador(a) & Renato de Oliveira & Tereza Correia da Nobrega Queiroz \\
\hline $\begin{array}{l}\text { Ano de } \\
\text { Conclusão }\end{array}$ & 2011 & 2018 \\
\hline Instituição & $\begin{array}{l}\text { Universidade Federal do Rio Grande do } \\
\text { Sul (UFRGS) }\end{array}$ & $\begin{array}{l}\text { Universidade Federal Da Paraíba } \\
\text { (UFPB) }\end{array}$ \\
\hline Tipo & DISSERTAÇÃO & TESE \\
\hline Área & Ciências Humanas - Sociologia & Ciências Humanas - Sociologia \\
\hline $\begin{array}{l}\text { Base de } \\
\text { Dados }\end{array}$ & CAPES e OATD & CAPES \\
\hline
\end{tabular}

Quadro 7 - Informações básicas sobre a tese e a dissertação

Fonte: Elaborado pelas autoras a partir da pesquisa autoral de caráter bibliográfico.

Correspondem, respectivamente, a trabalhos de conclusão dos cursos de mestrado e doutorado acadêmico em instituições públicas brasileiras e escritos em língua portuguesa. Após a leitura na íntegra, sistematizamos os objetivos, objeto de estudo, enfoque metodológico, fontes e principais resultados: 


\begin{tabular}{|c|c|c|}
\hline & Prolo (2011) & Silva (2018) \\
\hline Objetivos & $\begin{array}{l}\text { - Analisar o processo de formação de um } \\
\text { coletivo de estudantes da Universidade } \\
\text { Federal do Rio Grande do Sul (UFRGS), } \\
\text { intitulado Grupo de Trabalho de Ações } \\
\text { Afirmativas (GTAA). }\end{array}$ & $\begin{array}{l}\text { - Analisar se de fato a mudança na } \\
\text { base social (classe) da universidade } \\
\text { pública federal reflete um novo } \\
\text { momento das mobilizações } \\
\text { estudantis pautadas na } \\
\text { sobrevivência/permanência do } \\
\text { estudante na universidade e como o } \\
\text { estudante se torna um sujeito político } \\
\text { se inserindo em movimentos } \\
\text { coletivos de mudança no contexto } \\
\text { atual da expansão e retração do } \\
\text { ensino superior. }\end{array}$ \\
\hline $\begin{array}{l}\text { Objeto de } \\
\text { Estudo }\end{array}$ & $\begin{array}{l}\text { - O processo de formação de um coletivo } \\
\text { de estudantes na UFRGS, intitulado Grupo } \\
\text { de Trabalho de Ações Afirmativas (GTAA). }\end{array}$ & $\begin{array}{l}\text { - A participação de jovens } \\
\text { universitários, através do movimento } \\
\text { estudantil. }\end{array}$ \\
\hline $\begin{array}{c}\text { Enfoque } \\
\text { Metodológico }\end{array}$ & Qualitativo & Qualitativo \\
\hline $\begin{array}{l}\text { Principais } \\
\text { Referenciais } \\
\text { Metodológicos }\end{array}$ & $\begin{array}{l}\text { - Gabriel Feltran (2006) experiência } \\
\text { individuais e coletivas (análise de } \\
\text { trajetórias). }\end{array}$ & $\begin{array}{l}\text { - Laville e Dionne (1999) em estudo } \\
\text { de caso; } \\
\text { - Beaud e Weber (2015) em estudos } \\
\text { etnográficos. }\end{array}$ \\
\hline Fontes & $\begin{array}{l}\text { - Entrevistas abertas realizadas com os } \\
\text { membros do GTAA }\end{array}$ & $\begin{array}{l}\text { - Levantamento bibliográfico; } \\
\text { - Análise de Indicadores Sociais } \\
\text { (MEC e INEP); } \\
\text { - Etnografia com/nos Movimentos } \\
\text { Estudantis (ME); } \\
\text { - Entrevistas com estudantes. }\end{array}$ \\
\hline $\begin{array}{l}\text { Principais } \\
\text { Referenciais } \\
\text { Teóricos }\end{array}$ & $\begin{array}{l}\text { - Sidney Tarrow (2009) sobre a 'estrutura } \\
\text { de oportunidades políticas', que refere-se } \\
\text { às condições estruturais dos contextos } \\
\text { sociais para que determinados indivíduos } \\
\text { engajem-se coletivamente; } \\
\text { - José Albuquerque (1977), Marialice } \\
\text { Foracchi (1965) e Gilberto Velho (1999) } \\
\text { sobre as noções e possibilidades de } \\
\text { constituição de 'projeto' de ações coletivas; } \\
\text { - Alberto Melucci (1995, 2001, } 2004) \text {, sobre } \\
\text { os fatores conferem a um grupo sua } \\
\text { 'unidade'. }\end{array}$ & $\begin{array}{l}\text { - Thompson (7981, } 1984 \text { e 1987), a } \\
\text { partir do conceito de experiência; } \\
\text { - Bourdieu (1983, 1996, 2011, 2012), } \\
\text { com o conceito de campo político, } \\
\text { habitus, e entre outros; } \\
\text { - Eder Sader (1988), com a noção de } \\
\text { sujeito coletivo que desenvolve } \\
\text { práticas de ação coletivas a partir do } \\
\text { reconhecimento de interesses em } \\
\text { comum. }\end{array}$ \\
\hline Resultados & $\begin{array}{l}\text { - A formação do GTAA foi um processo de } \\
\text { organização coletiva pautado em } \\
\text { questionar as dinâmicas político- } \\
\text { institucionais. } \\
\text { - O GTAA constituiu-se em uma estrutura } \\
\text { de oportunidades políticas para } \\
\text { organização coletiva, com envolvimento } \\
\text { dos membros do grupo, de outros atores } \\
\text { da instituição e de não vinculados a esta. } \\
\text { - A pauta das cotas na Universidade foi } \\
\text { adotada pelo coletivo GTAA como uma } \\
\text { forma dos atores atribuírem significados } \\
\text { para suas trajetórias enquanto graduandos; } \\
\text { e culminou na construção da proposta e } \\
\text { aprovação da Decisão n } 134 \text { de } 2007 \text { que } \\
\text { instituiu o programa de ações afirmativas } \\
\text { na UFRGS. }\end{array}$ & $\begin{array}{l}\text { - O reconhecimento recíproco das } \\
\text { vulnerabilidades socioeconômicas } \\
\text { gerou no grupo de estudantes o } \\
\text { desenvolvimento de uma identidade } \\
\text { comum, estabelecendo laços de } \\
\text { sociabilidade e práticas de ação } \\
\text { política próprias. } \\
\text { - Através do movimento estudantil } \\
\text { que se dá os movimentos de } \\
\text { mudança, no campo político } \\
\text { universitário, com a incorporação de } \\
\text { novos atores, de novas demandas e } \\
\text { a afirmação de formas peculiares de } \\
\text { ações coletivas. }\end{array}$ \\
\hline
\end{tabular}

Quadro 8 - Abordagem de pesquisa na dissertação e na tese.

Fonte: Elaborado pelas autoras a partir da pesquisa autoral de caráter bibliográfico.

Em sua dissertação, Prolo (2011) analisou processo de formação do coletivo intitulado Grupo de Trabalho de Ações Afirmativas (GTAA), composto por estudantes da Universidade Federal do Rio Grande do Sul. Esse coletivo se propôs a estudar e reivindicar a implementação do sistema de cotas, nas modalidades étnico-racial e socioeconômica, na referida universidade. O processo de formação e debates se iniciou no final do ano de 2005 e se estendeu até 2007 , quando foi aprovada a resolução que implementou o programa de 
ações afirmativas na UFRGS. Uma das principais contribuições desse estudo foi para pensar as futuras pesquisas sobre ações coletivas, em cenários onde as formas de atuação política não sejam mais as mesmas que tradicionalmente serviram de base para outras pesquisas acadêmicas.

Em sua tese, Silva (2018) destaca que uma das pauta dos Movimentos Estudantis em universidades, em especialmente na UFPB, e nas últimas décadas, foram as condições de Classe (redistribuição), que reivindicavam a assistência social/estudantil. Acrescenta que a partir de 2007, com a implantação de ações governamentais com vistas à ampliação e democratização do acesso à universidade, houve a ascensão de camadas populares da sociedade brasileira nesta área de ensino, o que intensificou tal pauta. Segundo o autor, as mobilizações e atos políticos do movimento estudantil evidenciam a precariedade da assistência ao estudante, interferindo diretamente na permanência daqueles em situação de vulnerabilidade socioeconômica. O foco da sua pesquisa é nas mudanças de base social que estão ocorrendo nas universidades públicas federais, que refletem num novo momento de mobilizações, pautadas na sobrevivência/permanência, tornando o estudante da universidade um sujeito político. Não entra diretamente na seara da chegada de pessoas negras, indígenas, deficientes e outros oprimidos, com pautas de reconhecimento. Ou seja, o autor trata das mudanças no campo político universitário com a chegada do estudante com vulnerabilidade econômica.

\section{I CONSIDERAÇÕES FINAIS}

A construção deste 'Estado da Questão', para além da revisão de literatura, se configurou numa posição da pesquisa em relação ao seu objeto de estudo e na elaboração de um texto narrativo, com esforços para trazer a concepção de ciência e a contribuição epistêmica no campo de conhecimento. O desenho da narrativa obedeceu à ordem e aos critérios com proposição descritiva e ensaios analíticos. Os mesmos dados, entregues a outras(os) pesquisadoras(es), possivelmente teriam uma nova forma de narrar, não necessariamente o seu conteúdo (THERRIEN \& THERRIEN, 2004).

No total, compuseram o estudo 1.488 (mil quatrocentos e oitenta e oito) fontes de informações especializadas. Na tabela abaixo, segue uma síntese do que foi descrito e analisado ao longo desta construção: 


\begin{tabular}{|l|c|c|c|}
\hline & $\begin{array}{c}\text { Número de fontes } \\
\text { localizadas }\end{array}$ & $\begin{array}{c}\text { Número de fontes } \\
\text { sobre o tema geral: } \\
\text { políticas de ação } \\
\text { afirmativa para a } \\
\text { educação superior }\end{array}$ & $\begin{array}{c}\text { Número de fontes sobre } \\
\text { o tema específico: } \\
\text { participação política de } \\
\text { estudantes cotistas }\end{array}$ \\
\hline Artigos & 230 & 209 & 4 \\
\hline Livros & 353 & 168 & 1 \\
\hline $\begin{array}{l}\text { Teses \& } \\
\text { Dissertações }\end{array}$ & 905 & 582 & 2 \\
\hline \multicolumn{1}{|c|}{ TOTAL } & $\mathbf{1 . 4 8 8}$ & $\mathbf{9 5 9}$ & $\mathbf{7}$ \\
\hline
\end{tabular}

Tabela 4 - Síntese numérica das fonte analisadas.

Fonte: Elaborado pelas autoras a partir da pesquisa autoral de caráter bibliográfico.

Sobre o tema geral, contatamos uma predominância quantitativas e qualitativas dos debates sobre raça, racismo e relações raciais no Brasil, especialmente com problematizações e intersecções do tema quanto ao acesso à Educação Superior. No gráfico abaixo, é possível visualizar um panorama em porcentagens das abordagens temáticas nas 959 (novecentas e cinquenta e nove) fontes que compuseram o estudo:

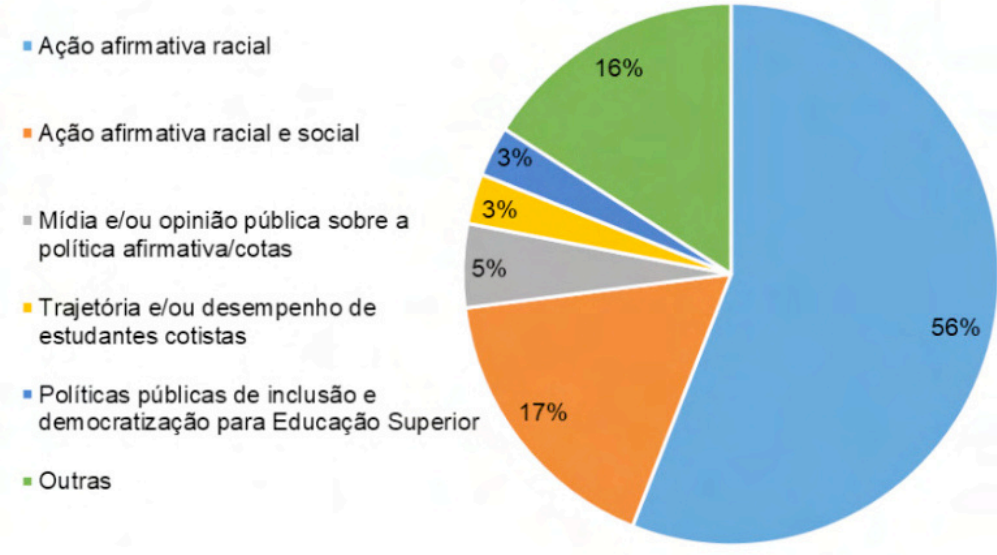

Gráfico 2 - Principais abordagens temáticas nas fontes

Fonte: Elaborado pelas autoras a partir da pesquisa autoral de caráter bibliográfico.

Nas exposições sistemáticas encontramos contribuições que possibilitaram reflexões significativas sobre a participação política de estudantes em diferentes formas e perspectivas. Porém, quanto ao tema específico em questão, os resultados mostram a escassez da abordagem indireta e inexistência de abordagem direta.

Contudo, a participação política de estudantes cotistas na construção das políticas afirmativas em universidades públicas é uma ferramenta essencial (consultiva e/ ou deliberativa), que requer arranjos sociais que permitam a interação de todas e todos, considerando, pelo menos, duas condições: objetiva, na distribuição dos recursos materiais, 
assegurando a independência e voz; e subjetiva, na valoração cultural, expressando igual respeito às/aos participantes e assegurando igual oportunidade para amenizar as injustiças sociais (FRASER, 2010).

Destacamos a importância da justiça social participativa, democrática e paritária, para pessoas e coletivos estudantis em processo de inclusão nas Universidades, que ainda possuem um modelo de gestão educacional permeado pelo conservadorismo, que aflora (ainda mais) em períodos de tensão social, política e econômica, como na atualidade. Reflexões críticas sobre as arenas participativas na construção de políticas educacionais locais contribuem para a mitigação da cidadania, do direito à vida e da justiça social no sentido pleno (BUENO \& BATISTA, 2020; CARVALHO, 2016; FRASER, 2010).

Por fim, o que poderia ser novo? A contribuição sobre o tema específico investigado.

Pois, estudos nesse viés, implicariam em reflexões e observações sobre a própria universidade, enquanto instituição promotora de formação cultural e política, na responsabilização com a construção da justiça social participativa (Fraser, 2010), por meio da inclusão das/dos novas/ novos discentes nos processos de construção das políticas educacionais afirmativas no interior das instituições. As universidades públicas estão num processo de mudança em sua composição, nas formas de acesso, nas novas pedagogias, nos novos currículos, nas novas ações de permanência, e especialmente, nas novas formas de participação política com o ingresso das pessoas com direito às ações afirmativas.

\section{REFERÊNCIAS}

BATISTA, Neusa Chaves. Políticas públicas de ações afirmativas para a Educação Superior: o Conselho Universitário como arena de disputas. Ensaio, Rio de Janeiro, Fundação Cesgranrio, v. 23. p. 95-128, 2015.

BRASIL. Congresso Nacional. Lei $n^{\circ} 12.711$. Dispõe sobre o ingresso nas universidades federais e nas instituições federais de ensino técnico de nível médio e dá outras providências. Diário Oficial da União, Brasília, 2012. Disponível em: http://www.planalto.gov.br/ccivil Acesso em: 02 jun. 2020.

BUENO, Rita de C. Soares de Souza; BATISTA, Neusa Chaves. Protagonismo de estudantes cotistas na Ocupação Akilombada da Reitoria da UFRGS. Políticas Educativas. Vol. 13, nº 2. p. 39-50, 2020. Disponível em: https://seer.ufrgs.br/Poled/article/view/107362/58280.

CARVALHO, José Murilo de. Cidadania no Brasil: um longo caminho. $21^{\text {a }}$ ed. Rio de Janeiro: Civilização Brasileira, 254 p. 2016.

FRASER, Nancy. Scales of justice: reimagining political space in a globalizing world. New York: Columbia. Universiy Press, 294 p. 2010.

MAIA, Allan Jeffrey Vidal, et al. Juventude e política: observando a UFBA. In: SAMPAIO, Sônia Maria Rocha, org. Observatório da vida estudantil: primeiros estudos [online]. Salvador: EDUFBA, p. 169-186, 2011. 
PAIVA, Ângela Randolpho. Cidadania, reconhecimento e ação afirmativa no ensino superior. Civitas, Porto Alegre, v. 15, n. 4, p. 127-154, 2015.

PASSOS, Joana Célia dos. Relações Raciais, Cultura Acadêmica e Tensionamentos após Ações Afirmativas. Educação em Revista, [online]. 2015. Vol.31, n.2, p. 155-182. ISSN 0102-4698. http:// dx.doi.org/10.1590/0102-4698134242.

PROLO, Felipe. Possibilidades e oportunidades de atuação política: estudo sobre a formação do grupo de trabalho de ações afirmativas no processo de reivindicação por cotas no ingresso da UFRGS. Dissertação de Mestrado. Programa de Pós-Graduação em Sociologia. Porto Alegre: UFRGS, p. 1-128, 2011.

SAMPAIO, Sônia Maria Rocha (Org.). Observatório da vida estudantil: primeiros estudos [online]. Salvador: EDUFBA, 2011.

SILVA, Fabiano Pereira. Juventude, política e educação: a emergência do estudante precarizado no contexto da reforma do ensino superior, sua inserção no movimento estudantil e os conflitos no campo político universitário. Tese de Doutorado. Programa de Pós-Graduação em Sociologia. Porto Alegre: UFPB, p. 1-280, 2018.

SOUZA, Andreliza Cristina de; BRANDALISE, Mary Ângela Teixeira. Democratização, justiça social e igualdade na avaliação de uma política afirmativa: com a palavra, os estudantes. Ensaio: avaliação de políticas públicas educacionais. [Online]. vol.23, n.86, p.181-212, 2015.

THERRIEN, Silvia Maria Nóbrega; THERRIEN, Jacques. Trabalhos científicos e o Estado da Questão: reflexões teórico metodológicas. Estudos em Avaliação Educacional, v. 15, n. 30, p. 5-16. 2004. 